\title{
The location problem in social ontology
}

\author{
Frank Hindriks
}

Received: 14 April 2009 / Accepted: 12 October 2011 / Published online: 26 October 2011

C The Author(s) 2011. This article is published with open access at Springerlink.com

\begin{abstract}
Mental, mathematical, and moral facts are difficult to accommodate within an overall worldview due to the peculiar kinds of properties inherent to them. In this paper I argue that a significant class of social entities also presents us with an ontological puzzle that has thus far not been addressed satisfactorily. This puzzle relates to the location of certain social entities. Where, for instance, are organizations located? Where their members are, or where their designated offices are? Organizations depend on their members for their existence, but the members of an organization can be where the organization is not. The designated office of an organization, however, need be little more than a mailbox. I argue that the problem can be solved by conceptualizing the relation between social entities and non-social entities as one of constitution, a relation of unity without identity. Constituted objects have properties that cannot be reduced to properties of the constituting objects. Thus, my attempt to solve the Location Problem results in an argument in favor of a kind of non-reductive materialism about the social.
\end{abstract}

Keywords Constitution - Constitutive rule - Location · Organization · Non-reductive individualism · Normative power $\cdot$ Social ontology $\cdot$ Status

Mathematical, mental, and moral facts are difficult to accommodate within an overall worldview. Mathematical entities present an ontological puzzle to philosophers because they are abstract. How the relation between mental and physical properties should be conceptualized is complicated by qualia because of their inherently subjective phenomenology. And the moral domain resists reduction, many believe,

\footnotetext{
F. Hindriks $(\varangle)$

Faculty of Philosophy, University of Groningen,

Oude Boteringestraat 52, 9712 GL, Groningen, The Netherlands

URL: http://www.rug.nl/staff/f.a.hindriks/index

e-mail: f.a.hindriks@rug.nl
} 
because moral judgments are intrinsically action guiding. Social entities seem to possess no features that make it particularly difficult to fit them into our ontology, or so it would appear. An ongoing debate in the philosophy of the social sciences concerns the relation between the individual and the social level. This ontological issue used to be formulated in terms of the question whether a social whole can be more than the sum of its parts. ${ }^{1}$ Nowadays it is cast in terms of supervenience. Roughly, the individualist who invokes supervenience maintains that two worlds that are indiscernible with respect to individual properties must have the same social properties. ${ }^{2}$ The vast majority of contemporary theorists subscribe to ontological individualism. ${ }^{3}$ Contemporary controversies about the relation between the social and the individual tend to be methodological and concern the questions what macro explanations might add to micro explanations, and whether there are irreducible social laws or mechanisms. ${ }^{4}$

In this paper I argue that a significant class of social entities does present us with an ontological puzzle that has thus far not been addressed satisfactorily. It concerns the location of certain social entities. Where, for instance, is the location of electronic money? Is it the bank where the account is held? All we find there is a computer that keeps track of bank records. It is not clear that electronic money even has a physical location. ${ }^{5}$ A similar problem arises for organizations. On the one hand, it seems natural to say that organizations such as universities are located at the same place as the buildings they occupy. On the other hand, those buildings are in a sense only incidentally related to the activities conducted in name of such organizations. Nothing important needs to be lost when a university starts using different buildings. As organizations regulate interactions between people, it seems plausible to ascribe an important role to those people in an ontology of organizations, perhaps to the point of saying that the organization is wherever its members are. However, it appears to be possible for all members of an organization to be in a location other than that of the organization to which they belong. Just as the location of electronic money, then, the location of organizations is problematic. We have conflicting intuitions about the location of such social entities. And we seem to be left with no clear and convincing philosophical answer to the question of where they are located. This is what I shall call 'the Location Problem in social ontology'.

The main thesis of this paper is that the Location Problem can be solved by conceptualizing the relation between social entities and non-social entities as one

\footnotetext{
1 Oppenheim and Putnam (1958), Quinton (1976), MacDonald and Pettit (1981), and Copp (1984) defend the idea that individual and social entities relate to one another as parts to wholes.

2 MacDonald and Pettit (1981), Mellor (1982), Currie (1984), and Kincaid (1986) Little (1991), Tuomela (1995), Sawyer (2002), and Zahle (2003) defend supervenience of social properties on individual properties.

3 See Epstein (2009, p. 188). As a self-professed holist (Gilbert 1989) belongs to the minority.

4 For explanations see Jackson and Pettit (1990), Weber and Van Bouwel (2002), and Marchionni (2008). For laws and mechanisms see Currie (1988), Kincaid (1990), Hedström and Svedberg (1998), and Sawyer (2003).

5 This example plays a prominent role in Smith (2007) critique of Searle (1995) social ontology. Smith argues that some institutional statuses such as electronic money have no physical basis (they are 'freestanding' institutional statuses). I address this problem in Hindriks (2011a). In this paper I am concerned with Ruben's Location Problem (see Sect. 1), which arises exactly because of the supposition that organizations have a physical basis. In Sect. 3.2 I discuss the question whether electronic money has a physical location.
} 
of constitution. Constitution is commonly seen as a relation between two entities that are spatially coincident but non-identical. I suggest that organizations can have institutional locations that need not coincide with the physical location of the people that constitute them. This fits nicely with the thesis that constitution is distinct from identity. However, it conflicts with the assertion that constitution requires spatial coincidence. I argue that this requirement is inadequate for organizations and that it should be replaced by what I call 'the Enactment Condition', a condition that relates the actions of organizations to those of their members. Because of this, I refer to the analysis of constitution that I propose and defend in Sect. 2 as 'the Enactment Account of Constitution'.

This Enactment Account entails that the institutional location of an entity need not coincide with its physical location, or, more precisely, with the location of the object(s) that constitute it. Hence, the former cannot be reduced to the latter. In Sect. 3 I develop the details of my account of organizations and generalize it to other social entities such as electronic money. This 'Status Account of Institutions', as I shall call it, paves the way for answering further ontological and methodological questions. In Sect. 4.1 I argue that the social does not supervene only on the individual but on the physical as well. I go on to defend and illustrate methodological holism in Sect. 4.2. In that section, I also argue that, in spite of its holist implications, the Enactment Account of Constitution enables me to make sense of the idea that social causation inheres in individual agents. Thus, my attempt to solve the Location Problem results in a forceful argument in favor of non-reductive materialism and methodological holism about the social.

\section{The location problem}

Ruben (1985) provides an elaborate discussion of the Location Problem. Using the Red Cross as his example, he maintains that it 'does not have any obvious physical location, although its headquarters does' (ibid., p. 14). Implicit in this claim is that the location of an organization cannot simply be identified with that of its headquarters. The main alternative Ruben considers is the idea that an organization is wherever its members are. He argues against this that the spatial location of social entities 'may not include the spatial location of their members' (ibid., p. 54). In support of this view he discusses a hypothetical example concerning the Red Cross:

Imagine a tour of a country with no national Red Cross (Albania perhaps) by a group of individuals who stand in any relationship to the Red Cross one might like to single out-Red Cross workers, or officials, or executives, or whatever. Let their tour of the country be in an official Red Cross capacity. Locating those individuals in that country for however long a period does not necessarily bring it about that the Red Cross can also be located in Albania. That is, the spatial location of the Red Cross, assuming it has one, may not even include the spatial locations of designated individuals who bear some special relationship to it. They can be where it is not. (Ibid., p. 54)

He uses this example to criticize the idea that the relation between social entities and their members might be a mereological one. This idea has received perhaps its most 
prominent defense by Oppenheim and Putnam (1958). If Ruben's argument works, it has to be abandoned. Given that the spatial location of a whole includes the spatial locations of its parts, the fact that the members of an organization can be where the organization is not does indeed seems to entail that the relation between these entities is not a mereological one. The overall conclusion Ruben draws is 'that individuals are not the parts of clubs, associations, or organisations, whether or not these later [sic] have spatial location' (ibid., p. 54; see also Uzquiano 2004).

Ruben leaves it open that these kinds of social entities have no location whatsoever. Accepting this, however, is rather unattractive, at least for those who, like me, want to accommodate organizations in a naturalistic ontology. Let me explain why. On plausible naturalist views of social entities they are determined by non-social and ultimately physical entities. Given that physical entities have a location, it appears that the naturalist cannot deny that the social entities that depend on them have a location as well. The salient alternative to denying that they have a location is to say that the location of social entities coincides with the location of the entities on which they depend. The Red Cross example makes it problematic to accept this answer. The challenge that the Location Problem presents to the naturalist, then, is to explain how this answer can be correct after all, or to provide an alternative (positive) answer to the question of the location of organizations. ${ }^{6}$

Ruben distinguishes organizations from groups. He draws this distinction by means of examples and does not offer an account of it. On his view, teams and tribes are groups, while clubs and associations are organizations. In contrast to the case of organizations, he does not regard the location of groups as a problematic issue. He accepts the idea that groups have a spatial location. What is more, he regards it as 'quite natural to identify [the location of a group] with the sum of the spatial locations of the group's members' (ibid., p. 55; cf. Effingham 2010). Whence this difference? In support of these claims, Ruben appeals to intuition:

There is nothing counterintuitive about admitting that some group like the Romany might have parts of its spatial location in Iceland if there are some Gypsies there, in the way in which it was counterintuitive to locate part of France in Iceland on the same grounds. Indeed, if there are French persons in Iceland, then it seems acceptable to believe that part of the group of French persons is located in Iceland, in spite of the fact that no part of France can be so located. (Ibid.; see also p. 75)

This does indeed appear to be plausible. The upshot is that we have reason to think that groups such as teams, tribes, social classes, and families are located wherever their members are, while clubs, associations, or more generally organizations are not.

Let me explicate the Location Problem in more detail. My main example is that of a limited liability company, which is an organizational form that enables its members

\footnotetext{
${ }^{6}$ Ruben (1985) is attracted to the view that some social entities, including countries, or states, are nonmaterial, do not supervene on material entities, but are nevertheless spatially locatable. However, he also suggests that such entities are 'parasitic on material entities' in particular because 'a notion of public space presupposed material particulars' (ibid., p. 74). In this paper I explore whether it is feasible to develop a less radical view, one that does not require a blanket rejection of supervenience (see Sect. 4).
} 
to limit their liability to non-members to the amount of money they invest. In order to create such a company a certificate of organization needs to be drafted. Such a certificate must state the name of the limited liability company, the geographical and mailing addresses of the initial designated office and the name and street and mailing addresses of the company's initial agent for service of process. So in response to the question where a particular limited liability organization is located it is natural to provide the address of the designated office (or perhaps the address of the principal office, if this is different). ${ }^{7}$

At the same time, however, there is something odd about this answer. The designated office might be little more than a mailing address. The members of the company might spend hardly any time there. The main purpose of forming a limited liability company is to limit the liability of those who become its members. In light of this, it is natural to regard a limited liability company as an institutional status that is imposed on a collection of individuals. This makes it plausible to hold that the location of a limited liability company must be that of its members. However, it is hard to see how both claims can be true. It makes sense to say that an organization is located in the country or state where its designated (or principal) office is located. At the same time, however, it is possible for all its members to be in another country. So it seems that we have to choose between two ways of identifying the location of an organization-its address and the location of its members. And we are left without an argument for preferring one to the other. The possibility that neither is true cannot even be excluded. This is the Location Problem as it arises from Ruben's arguments.

The Location Problem poses a challenge for social ontology. It seems to rule out any straightforward reduction of organizations to individuals. After all, if they were reducible to individuals, they would have the same location as those individuals. Rejecting reductionism as such, however, does not solve the Location Problem. Many versions of non-reductive materialism require spatial coincidence between the constituted and constituting object. The Location Problem, then, seems to rule out most if not all of the available views concerning the relations between different ontological levels. In Sect. 2, I shall develop a conception of constitution that does not require spatial coincidence. How it serves to solve the Location Problem is discussed in Sect. 2.4.

\section{Constitution is the solution}

\subsection{Physical and institutional locations}

In order to make sense of the thought that an organization might have a location that can differ from that of its members, more needs to be said about what organizations are. Raimo Tuomela (1995) has argued that organizations can be seen as systems of tasks and roles. Such systems embody formal and informal norms that govern the behavior of the members of organizations. Each member of an organization has a

\footnotetext{
7 My source for information on limited liability companies is the Revised Uniform Limited Liability Company Act drafted by the National Conference of Commissioners on Uniform State Laws in the United States in 2006.
} 
particular role within such a system and is expected to perform certain tasks. These ideas are very useful for understanding the internal structure of organizations. However, organizations also interact with outsiders, people who are not members. An adequate conception of organizations also requires an understanding of such external relations.

Consider limited liability companies (LLCs) once again. LLCs have several attributes in common with (most) other organizations. They can, for instance, sue in their own name. What is distinctive about them is that by forming an LLC the individuals involved limit their liability in respect of non-members to the amount of money they invest. As right and liability are normative notions, it is natural to refer to attributes such as limited liability and the right to sue as 'normative attributes' or 'normative powers'. The legal powers that are characteristic of LLCs determine its legal status. More generally, I shall say that the (legal and non-legal) normative powers that are characteristic of an institution form its status. Creating an LLC, then, is a matter of imposing a particular institutional status on a collection of individuals. ${ }^{8}$

In order to appreciate how this is relevant to the Location Problem, we need to have a better understanding of why an address of a designated office is required for creating and maintaining an LLC. One of the purposes that such an address serves is facilitating communication between the Secretary of State and the LLC. It also determines which laws apply to an LLC. An LLC is governed by the laws of the state in which its designated office is located. Thus, apart from a pragmatic communicative purpose, the location of a designated office serves an important legal purpose.

The insight that the official location of an LLC serves a legal or institutional purpose can be used to shed light on the Location Problem. I shall refer to a location that serves an institutional purpose as 'an institutional location'. Some of our intuitions concerning the location of organizations pertain to their institutional location. This is why it makes sense to us to say that the members of an organization such as the Red Cross can be where the organization is not. After all, the institutional location of the Red Cross does not change when its members travel to other places. At the same time, members play a crucial role in organizations. In fact, a few paragraphs back I have suggested that the creation of an LLC is a matter of imposing the status of LLC on a particular collection of individuals. This could easily be taken to suggest that the location of an LLC is identical to that of its members. It certainly seems to make it problematic to say that the places where its members are at is irrelevant to the location of an organization.

The upshot is that the Location Problem arises because some of our intuitions about the location of an organization pertain to its institutional location, whereas others pertain to the location of its members. For the moment, I shall refer to the location of an organization's members as its non-institutional or physical location. Distinguishing between an organization's institutional location and its physical location does not yet provide a solution to the Location Problem. It is not obvious that the idea that an organization might have both a physical and an institutional location makes sense. In

\footnotetext{
8 This conception of a status and its normative powers is inspired by Searle $(1995,2010)$ conceptions of status functions and deontic powers. It lies at the heart of the status account of institutions that I introduce in Sect. 3.1 and which I discuss more elaborately in Hindriks (2008a, 2009).
} 
Sects. 2.2 and 2.3 I shall develop an account of the constitution of organizations that serves to make this idea intelligible.

\subsection{Spatial coincidence and enactment}

Consider a statue and the piece of marble of which it is made. The statue coincides spatially with the piece of marble. It is not identical to it, however, because the piece of marble might have existed long before the statue was created. The piece of marble only constitutes a statue because it bears a certain relation to an art world. So its existence depends not only on the piece of marble, but also on its context. As this example reveals, constitution is a relation of unity without identity (Baker 1997, 2000, 2007). The unity of constitution is usually taken to consist in material (and therefore spatial) coincidence of the constituted object and the constituting object. ${ }^{9}$ Constitution differs from identity in that the objects between which this relation obtains have different properties, most notably different persistence conditions. As I already indicated, a piece of marble can exist before coming to constitute a statue.

A piece of marble constitutes a statue exactly if the piece of marble is situated in an appropriate context. ${ }^{10}$ The piece of marble and the art world play different roles in the constitution relation. The art world provides for the context within which the piece of marble is a statue. Outside that context, the piece of marble would not be a statue. When the piece of marble constitutes a statue, the location of that statue can be identified with that of the piece of marble. The context plays a crucial role in the constitution of the statue, but does not affect its location.

It is attractive to conceive of the relation between organizations and their members in terms of constitution because they have different persistence conditions. An LLC is created by people who are among its first members. These members existed prior to the LLC, just as a piece of marble exists before the statue comes into existence. An LLC can also remain in existence when its founding members die. There is reason to believe that Baker's account of constitution is particularly useful as a point of departure for developing an account of constitution that solves the Location Problem because of the role that circumstances or context play in it. Organizations owe their existence to the context in which they operate, just as statues owe their existence to their relation to an art world. The existence of an LLC, for instance, depends on the Secretary of State and on the relevant legal system.

The Location Problem reveals that the condition of spatial coincidence is problematic for organizations. For this reason I shall present an account of constitution in which this condition plays no role. By analogy with differing persistence conditions, I propose, the spatial location of a constituted object can be distinct from that of the constituting object. This implies that the unity of the constitution relation has to be conceived of in other terms. One candidate for replacing the spatial coincidence

\footnotetext{
9 In addition to Baker, see Doepke (1982), and Thomson (1998). Naturally, this condition is also satisfied by accounts on which constitution is a kind of identity (Noonan 1993). Note that the notion of realization can also be used for developing an account of non-reductive materialism (see Gillett 2002).

10 The example and the idea that circumstances or contexts are relevant to constitution are taken from Baker (1997, 2000).
} 
condition is Robert Wilson (2005, p. 67) condition of agency coincidence. Two agents are agency coincident just if they undertake precisely the same actions at all times. ${ }^{11}$ This condition cannot be correct. First, even if all acts of organizations were to coincide with the same actions performed by its members, many actions undertaken by those members are not performed in their capacity of members. And these are not organizational actions. The agency coincidence condition, however, entails that they are (also) actions performed by the organizations of which the individuals are members. This is not the case. The second problem that the agency coincidence condition faces is that organizational actions often involve individual actions of a different kind. A construction company, for instance, can build an apartment building without any of its employees doing so. Building an apartment building does not lie within the powers of any individual human being. The same holds for the performance of a symphony. The members of an orchestra play their individual parts, which together constitute the performance. Only the orchestra as a whole performs the symphony. Examples such as these violate Wilson's condition that organizations and their members perform the same actions. ${ }^{12}$

As an alternative, I propose what I call 'the Enactment Condition'. At the heart of this condition lies the idea that members enact the actions of their organization. Just as agency coincidence, enactment does justice to the intuition that constitution is similar to identity in an important respect. The notion of enactment does not suffer from the problems that agency coincidence faces. An enactment condition need not refer to kinds of actions. As a consequence, such a condition can allow for organizational actions that are of a kind distinct from the actions that members perform. Furthermore, the notion of enactment is flexible in that it allows for the possibility that some of the actions that members perform are irrelevant to the actions of the organization. The claim that members enact organizational actions does not entail that all actions that members perform are implicated in organizational actions.

There is one problem, however, with the idea that members enact organizational actions. An organization might, for instance, hire a lawyer to execute certain organizational actions. The lawyer does not thereby become a member of the organization. This does not pose a big problem for formulating an enactment condition. It only requires an additional clause concerning the authorization of non-members to act in the name of the organization. The Enactment Condition that I propose is this:

Any action of an organization is enacted by some of its members, or by one or more agents who have been authorized by the organization.

It is not obvious, however, that this Enactment Condition does justice to the idea that constitution is a relation of unity. Whereas the first clause by itself seems to support it, the second clause could be taken to undermine it. On closer inspection, however,

\footnotetext{
11 The precise formulation of Wilson's proposal is this: 'Two agents are agency coincident at $t$ just if they undertake precisely the same actions at $t$. To be agency coincident simpliciter is to be agency coincident at all times (cf. spatial coincidence).' (Wilson 2005, p. 67)

12 Zahle (2003) argues that joint actions that are of a different kind than the individual actions they consist of present a particularly strong case against reducing the social to the individual (see Sect. 4 for more on this).
} 
it poses no threat. It only reveals that the intimate relation that organizations bear to the members that constitute them does not reside so much in the actions that members perform. Instead, it resides in the normative powers that members have. The clause concerning authorization is not simply an addition to the first clause that solves a minor problem. Instead, it reveals why exactly the Enactment Condition is so crucial for capturing the idea that members constitute their organizations. Members have the capacity to act on behalf of their organization in virtue of the normative powers they have.

In Sect. 2.1 I proposed that creating an organization is a matter of imposing an institutional status on a collection of individuals. Furthermore, I put forward the idea that institutional statuses consist of normative powers. What becomes apparent now is that the normative powers of an organization depend on the normative powers of its members at least in the sense that an organization can only execute its normative powers if some of its members have executed some of the normative powers they have in virtue of their membership. How does this help to solve the puzzle concerning the lawyer who enacts organizational actions even though he is not a member of the organization? The second clause of the Enactment Condition requires that he be authorized by the organization. An organization can authorize a non-member to act on its behalf only if some of its members execute their normative powers. The owner of an LLC could for instance sign a contract with the lawyer and thereby authorize him to sue on behalf of the company. This reveals that even if the only action the members enact is that of authorizing a lawyer to execute all the organization's actions, an organization still has an intimate relation with its members. They have hired her on behalf of the organization, and they have the power to terminate the contract (under certain conditions). ${ }^{13}$

All this suggests that the Enactment Condition can play a central role in an ontology of organizations. Insofar as the Location Problem is concerned, it removes the only barrier for solving it by means of the notion of constitution. It turns out to be feasible to develop an account of constitution that does not require spatial coincidence. Wilson's agency coincidence does not provide for a suitable alternative. It has the awkward consequence that individuals who belong to an organization always act in their capacity as members. And it would surely be odd to say, for instance, that the Red Cross acts where its members act when they happen to be on holiday. Another unattractive feature of agency coincidence is that non-members cannot enact organizational actions. The Enactment Condition avoids both problems. The step that remains to be taken in order to solve the Location Problem is embedding the Enactment Condition in an overall account of the constitution of organizations. This is the topic of the next section.

\subsection{The enactment account of constitution}

Constituted objects have persistence conditions that differ from those of the constituting object. A constituting object can exist prior to the constituted object. The members of an LLC, for instance, can exist prior to the creation of the LLC. An adequate account

\footnotetext{
$\overline{13}$ I thank an anonymous referee for this example and for pressing me to elaborate on the Enactment Condition.
} 
of constitution has to capture this possibility. The thing to do, then, is to develop an account of constitution that includes the following condition: it is possible for the collection of individuals that in fact constitutes a particular organization not to form that organization (this modal condition is condition 1 of the account presented below).

I have suggested that constituted objects owe their existence to the fact that the constituting objects occur in a particular context. People constitute an organization only if they meet the conditions for being a member of such an organization. In case of an LLC, these conditions require them to supply an address of a designated office and to sign an operating agreement. When a collection of individuals meets these (and other) conditions it cannot but constitute an LLC. This is ensured by legislation. Those legal conditions are the contextual conditions that people have to meet in order to constitute an LLC. In order to capture this aspect of constitution another modal condition needs to be added. Roughly, the idea is that, necessarily, when a constituting object meets the appropriate contextual conditions it constitutes the constituted object (condition 2).

I shall use ' $Y$ ' as a schematic letter for institutional statuses, and I shall refer to the relevant contextual conditions as $Y$-favorable conditions. $Y$-favorable conditions are those conditions that an object has to meet in order to constitute an entity that has an institutional status. In Sect. 3 I shall elaborate on what these conditions are. To provide initial support for the claim that such conditions can actually be specified, let me say that for organizations such as LLCs the favorable conditions are determined by law (see note 7).

In the terms just introduced, the proposal is that one or more entities have a status $Y$ if they meet the $Y$-favorable conditions. As indicated above, this is a matter of necessity (condition 2). Furthermore, the $Y$-favorable conditions have to be met in fact (condition 3). Even though a constituting entity necessarily constitutes an institutional entity if it meets the relevant $Y$-favorable conditions, the relation of constitution itself is a contingent relation. The reason for this is that whether or not an entity of the relevant kind occurs in $Y$-favorable conditions is a contingent matter (condition 3). $Y$-favorable conditions answer the question in virtue of what something is what it is (Baker 2000, p. 41). An appropriate answer to the question why certain people constitute an LLC is: because they meet the LLC-conditions. Among other things, they have supplied the address of a designated office and they have signed an operating agreement.

Of course, the Enactment Condition discussed in Sect. 2.2 has to be included as well (condition 4). This condition facilitates the formulation of a further condition that serves to capture another aspect of the difference in persistence conditions. A constituted object can survive changes in its composition. A ship, for instance, can survive replacements of some of its parts. And an LLC need not go out of existence when some of its members leave the organization. This can be captured by requiring that it is impossible for a $Y$-organization to exist without there being a collection of individuals that enacts its actions or authorizes one or more agents to do so (condition 5).

The proposed account is the combination of the five conditions discussed:

One or more individual agents constitute an organization with status $Y$ if and only if

1. It is possible that the agents do not form a $Y$-organization.

2. Necessarily, the agents form a $Y$-organization if they meet the $Y$-favorable conditions. 
3. The $Y$-favorable conditions are satisfied.

4. Any action of the $Y$-organization is enacted by (some of) the agent(s), or by one or more agents that it has authorized.

5. It is impossible for a $Y$-organization to exist without there being one or more agents who enact its actions or who authorize other agents to do so.

Because of the crucial role that the Enactment Condition (4) plays, I shall refer to this set of conditions as 'the Enactment Account of Constitution'.

\subsection{A solution of the location problem}

How can the Enactment Account of Constitution be used to solve the Location Problem? In Sect. 2.1 I suggested that organizations have physical and institutional locations. I am now in a position to phrase this with greater felicity. An organization only has one location, and that location is determined by the institutional or legal context. However, an organization consists of people, and the locations of those people can differ from the location of the organization. The location of the collection of individuals that constitutes an organization is the sum of the spatial locations of the members of the organization (cf. Effingham 2010). ${ }^{14}$ So it is literally true that an organization can be where its members are not. Whether an organization and the noninstitutional object that constitutes it are in one and the same location is a contingent matter.

In order to get to the heart of the Location Problem, it will be useful to say more about the relation between organizations and groups. Organizations such as sole proprietorships consist of one individual only. The Enactment Account of Constitution is silent on the relations that obtain between individuals in organizations that consist of more than one member. For all it says, they could be only loosely connected to one another. It is, however, rather plausible that the individuals who constitute an organization form a social group. Elsewhere I have argued that a social group exists exactly when several individuals have collectively accepted a collective decision mechanism, which serves to determine both what to do and who belongs to the social group (see my 2008a). Presumably the individuals who constitute an LLC collectively accept a collective decision mechanism when they sign an operating agreement. If so, they form a social group.

There is more to organizations, however, than collective decision mechanisms. Organizations involve institutional statuses. Individuals within an organization can have institutional statuses such as that of a CEO. Furthermore, an organization as such can have an institutional status. Think of a social group that has acquired the status of an LLC. Acquiring such a status is a matter of incorporating or institutionalizing the organization. Ruben's claim that groups are where their members are amounts to the assertion that the location of the members determines the locations of groups that

\footnotetext{
14 Some members matter more to the organization to which they belong than others. Tuomela (1995, p. 176) distinguishes between authorized and non-authorized members. Only authorized members have the (normative) power to act on behalf of the organization. It may be that only authorized members constitute an organization (whether this is the case depends on the applicable $Y$-favorable conditions). If so, only their locations are relevant.
} 
are not organizations. Organizations can have locations that are distinct from those of their members. Given how organizations differ from mere social groups, this potential divergence in location must be due to the fact that only the former involve institutional statuses. This is corroborated by the examples discussed earlier. Consider, for instance, the fact that an LLC is governed by the laws of the state in which its designated office is located (Sect. 2.1). Such a legal or institutional location facilitates a divergence in locations. ${ }^{15}$

The Enactment Account of Constitution can be used to evaluate Gabriel Uzquiano (2004, p. 137) claim that the US Supreme Court is wherever the Supreme Court Justices are. The status of this claim turns on whether the US Supreme Court is merely a social group or also an organization. Without realizing it, Uzquiano gives the answer himself: ' $[I] n$ the case of the Supreme Court, permanence of powers, rules, and procedures matters to the Supreme Court's continued existence more than permanence of members does' (2004, p. 150). This passage concerns the persistence conditions of the Supreme Court. It implies that the very existence of the Supreme Court depends on powers, rules, and procedures. The relevant powers are normative powers that make up a status. Hence, the Supreme Court is an organization and not a mere social group. This in turn implies that, in contrast to what Uzquiano maintains, its location and those of its members can come apart.

Lynne Rudder Baker (2000) draws a distinction between essential and derivative properties, which could be used to argue that the institutional location of an organization is an essential property of that organization, whereas its physical location is a derivative property. This would entail that in some sense organizations can have two kinds of locations. Shouldn't this claim be met with an incredulous stare? I do not think so. The claim that an entity has two kinds of locations is not less plausible than the claim that an entity has two kinds of persistence conditions. Yet the (attenuated) sense in which the latter is true is the same in which the former is true. The claim that organizations have physical or non-institutional locations simply means that they are constituted by collections of individuals the locations of which need not coincide with those of the organizations. This is an unambiguous claim. The fact that the earlier claim can be confusing is closely related to why the Location Problem is a problem in the first place. In the absence of a proper theory it appears that we have conflicting intuitions about the location of organizations. Once an account of constitution such as the one presented here is in place, it is apparent that the intuitions do not conflict but pertain to different albeit closely related things: organizations and the collections of individuals that constitute them. ${ }^{16}$

\footnotetext{
15 In Hindriks (2008a) I distinguish corporate agents from organizations. Organizations have internal structure in the sense that (at least some of) its members have institutional statuses. Corporate agents are organizations that have acquired an institutional status as such. It seems plausible that only corporate agents have institutional locations. If so, what follows applies strictly speaking only to organizations that are corporate agents.

16 There is reason to believe Ruben would support this solution of the Location Problem. Although he never commits himself to a particular solution, he writes: "if these things do have a spatial location, they are to be located wherever they have branches or affiliates, and that these latter exist wherever they have been duly constituted as existing.' (Ruben 1983, p. 225)
} 


\section{Statuses and constitutive rules}

\section{1 $Y$-favorable conditions and institutional locations}

The Location Problem has been solved by developing an account of constitution that has no requirement of spatial coincidence. This Enactment Account of Constitution complements the Status Account of Institutions of which only the contours have been provided thus far (see my 2008a, 2009 for more elaborate discussions). Now it is time to fill in the details of the proposal and say more about what $Y$-favorable conditions are. This serves to further elucidate the nature and significance of institutional locations. In addition to this, I shall argue that other institutional entities can be analyzed along the same lines.

The notion of $Y$-favorable conditions can be elucidated in terms of that of a constitutive rule, or so I propose. Both John Searle and Alvin Goldman explicate institutional actions in terms of constitutive rules (although only Searle uses this term). According to Searle $(1969,1995)$, the structure of a constitutive rule is given by the schema ' $X$ counts as $Y$ in $C$ ' to which he refers as 'the counts-as locution'. Searle uses money as an example: 'Bills issued by the Bureau of Engraving and Printing (X) count as money (Y) in the United States (C)' (Searle 1995, p. 28). ${ }^{17}$ As before, the $Y$-term stands for an institutional status such as money. The $C$-term specifies a context, and the $X$-term describes the entity on which the status is imposed. It seems plausible to say that the entity described by the $X$-term constitutes the institutional entity at issue. Searle's use of the term 'constitutive rule' suggests that this is what Searle has in mind. However, he has next to nothing about what this relation of constitution might be. ${ }^{18}$

Goldman (1970) uses the notion of conventional generation in order to explicate what institutional actions are. He argues that actions such as signaling a turn in traffic, or checkmating one's opponent in chess, exist in virtue of rules, conventions, or social practices. These might be the rules of chess, or a rule such as 'extending one's arm out the car window while driving counts as signaling for a turn' (ibid., p. 25; emphasis added). Goldman goes on to argue that in most instances of conventional generation certain circumstances are essential to the performance of the institutional action. They might be the positions of the various pieces on the chessboard, or the fact that a particular person was driving a car when he extended his arm out of the window.

Goldman has commented on the relation between institutional actions and non-institutional basic actions. On his view, this relation is irreflexive, asymmetric, and transitive (ibid., p. 21). These are the properties that the relation of constitution is

\footnotetext{
17 Dollar bills are in fact issued by the Federal Reserve and not by the Bureau of Engraving and Printing.

18 Searle criticizes the claim that corporations are status functions imposed on collections of persons by arguing against the claim that corporations are identical to seems to those collections (2006, p. 24, 2010, p. 20). Also his claim that an object is a social object 'only under certain descriptions and not others' suggests that he regards the relation between institutional and non-institutional entities as one of identity (2003, p. 302; see also Smith 2007, p. 12). The Location Problem reveals that this conception of constitution is inadequate for organizations. The reason for this is that, if organizations were identical to the collection of its members, their locations would be identical as well.
} 
commonly taken to have (Wasserman 2004). And constitution has these properties on the account of constitution presented in Sect. 2.3. In light of this, it makes sense to say that Goldman has constitutive rules in mind when he appeals to rules in his account of conventional generation. What Searle and Goldman say about such rules also suggests that it is worthwhile to try and enrich the proposed analysis of constitution by invoking the notion of a constitutive rule.

Searle's counts-as locution is particularly useful for this purpose. It facilitates asking the right questions: What do $X, Y$, and $C$ stand for, and what does 'counts as' mean? To start with the latter, the example of money suggests an interpretation. Economists commonly take money to be a generally accepted means of exchange. It depends on the context at issue which kinds of objects are used as money. Those objects only are money because they are generally or collectively accepted as such in that context. The idea, then, is that an object of type $X$ is or constitutes an institutional object of type $Y$ in a context $C$ exactly if the relevant individuals collectively accept this (see Tuomela and Balzer 1999 and Tuomela 2002 for more on collective acceptance). In other words, the object of collective acceptance is a constitutive rule that specifies a context and a set of conditions that an object has to meet in that context in order to instantiate the relevant status.

How does this shed light on the notion of $Y$-favorable conditions? This discussion of constitutive rules reveals that there are several different kinds of $Y$-favorable conditions. There are in fact three subcategories. First, all the conditions that make up context $C$. Second, all the conditions captured by the $X$-predicate. Just as I shall refer to contextual conditions as $C$-conditions, I shall refer to these as ' $X$-conditions'. $X$-conditions are those conditions that an entity has to satisfy in order to constitute an entity with an institutional status $Y$ in a particular context $C$. $X$-conditions can be non-institutional conditions such as that you need to have a height of 64 to 77 inches in order to qualify as a pilot in the US Air Force. And third, collective acceptance of a constitute rule of the form ' $X$ is $Y$ in $C$ ' (on my view the phrase 'counts as' is redundant once the role of collective acceptance has been made explicit; see my 2008a, pp. 133-134; 2009, p. 263). I shall refer to this collective acceptance condition as the $A$-condition. The $A$-condition reveals that which conditions are favorable with respect to a particular institutional status $Y$ can only be answered relative to a particular group of people among whom this status is recognized. $Y$-favorable conditions consist of the combination of $X$-conditions, $C$-conditions, and the $A$-condition. ${ }^{19}$

It is important to distinguish between $X$-conditions and $C$-conditions in order to avoid confusion about what is internal and what is external to a particular status $Y$. As I have been concerned with US companies, the $C$-conditions of an LLC include the requirement that the institutional address is within the United States. As the address of the designated office has to be provided to the Secretary of State, another condition of LLCs is that there be (the position of) a Secretary of State. This has to be a contextual condition rather than an $X$-condition, because the Secretary of State is not

\footnotetext{
19 Recall that it is a necessity that an entity of the appropriate kind that occurs in $Y$-favorable conditions has the $Y$ status. Which conditions are $Y$-favorable, however, is a context-dependent and contingent matter (Baker 2000, p. 43). On my view this depends on the details of the constitutive rule that is in force in a particular group, i.e. on its $C$ - and $X$-conditions.
} 
a member of the LLC. More precisely, the LLC is not constituted by the Secretary of State, but by other individuals. A distinction between what is internal and what is external to the constituter of a status provides for a rough guide as to which conditions are $C$-conditions and which are $X$-conditions.

I venture that the notion of a status can be used to shed light on the ontology of any institutional entity. ${ }^{20}$ The familiar examples of money, marriage, and property rights clearly involve normative powers. And rights, obligations, and other normative powers also play a role in traffic rules and in the rules that are constitutive of etiquette. All the examples mentioned can also be explicated in terms of constitutive rules. What is distinctive of organizations is that they are statuses imposed on collections of individuals. Those individuals enact the actions of the organizations they belong to or authorize others to do so. Furthermore, organizations arrive at decisions due to the fact that their members rely on some mechanism for making decisions.

These ideas about statuses and constitutive rules can be used to say more about the nature and significance of institutional locations. Having an institutional location is practically convenient. The address of its designated office facilitates communication between the Secretary of State and an LLC. It is more practical for a Secretary of State to communicate with the LLC as such than with any of its members, in part because members can leave organizations and new ones can enter. However, the significance of an institutional location surpasses mere practical convenience. An institutional location is also a placeholder for the assignment of normative powers. And normative powers determine the practical significance of institutional entities. The location of an LLC bears on the laws that apply to it. Which laws apply depends on the state in which the designated office is located. An LLC can change its institutional location. If an LLC moves to another state, different laws will apply to it. The fact that changing location has real consequences confirms the idea that its institutional location is a genuine feature of an organization.

The constitutive rule of LLCs includes providing the Secretary of State with an address of a designated office as one of its conditions. ${ }^{21}$ Another one is drafting an operating agreement that regulates the interaction between the members. These are $X$-conditions that a collection of individuals has to meet in order to constitute an LLC. As it is a placeholder for the assignment of the relevant normative powers, creating an institutional location can be a straightforward matter. Often providing a mailing address is all there is to it. And sometimes a designated office is nothing more than a mailing address. All the productive activities of the organization can be undertaken elsewhere. Moreover, most, if not all members can reside elsewhere. Even so, the fact that the address of its designated office is what matters for legal purposes reveals that an institutional address can be of substantial practical significance.

\footnotetext{
20 Searle makes a similar claim for his notion of a status function in his 1995 and for his notion of a status function declaration in his 2010. These notions are closely related to my notions of status and normative power.

21 In Hindriks (2008a, 2009) I argue that institutional statuses are to be understood not only in terms of constitutive rules but in terms of what I call 'status rules' as well. There I explicate statuses in terms of status rules of the form ' $Y$ is $Z$ ', where $Z$ refers to a collection of normative powers. The notion of a status rule serves to clarify the relation between constitutive and regulative rules.
} 


\subsection{More location problems}

The distinction between the physical and institutional location of an organization enables us to make sense of the idea that organizations can be where their members are not and vice versa. There are, however, a couple of other puzzles that pose challenges to the ontology of organizations or institutions more generally. First, it is possible for two organizations to consist of exactly the same people. Second, it appears there can be organizations or (other) institutions without any members at all. Both possibilities pose a challenge to a constitution view of institutions. And both puzzles are Location Problems, because, as I discuss below, each of them involves conflicting (philosophical) intuitions about the location of an institutional entity.

As an example of the first option, consider an LLC and some kind of charitable foundation. Perhaps the LLC has been very successful and has made its members very rich. Those members may want to contribute to society through charity and do so through their own foundation. At a commonsense level there is nothing odd about such a case. However, from an ontological point of view it challenges some deeply cherished beliefs. An initially plausible adequacy condition for non-reductive materialism is that any object at one level constitutes or realizes at most one object at another level. A piece of marble can constitute at most one status; a body can constitute at most one person.

Baker (2007) has in fact explicitly ruled out this possibility in her account of constitution. As is common, her account includes a condition concerning spatial coincidence. In her account, this condition has a clause that requires any constituted object that has a particular kind of essential property and that is spatially coincident with the constituter to which the account is applied to be identical to the constituted object at issue (ibid., p. 161). This excludes the possibility of one collection of individuals constituting two organizations. However, it is perfectly conceivable that this does occur. Anthony Quinton (1976) and Hugh Mellor (1982) made this point more than thirty years ago. Quinton (1976, p. 21) points out that two groups can have the same members. Mellor accepts the claim that 'two people cannot be in exactly the same place at the same time', but goes on to note that 'two groups can' (1982, p. 65). Given that it is possible, we should of course refrain from ruling it out by stipulation. Fortunately the condition that an object can only constitute one object at a particular higher level is not part of the Enactment Account of Constitution presented in Sect. 2.3. The condition would have to be added to it as a requirement that is independent of the other conditions (cf. Baker 2007). The Location Problem under consideration implies that this should not be done. The Enactment Account allows for the possibility at issue as it stands. So if it is left untouched, it solves this Location Problem as well.

Again the solution is due to the fact that the account relies on an enactment condition rather than a material coincidence condition. Abstracting for the moment from the possibility of an organization authorizing nonmembers to act on its behalf, the possibility that is to be accommodated is that one and the same (collection of) individual(s) can enact the actions of two organizations. The thing to note is that people do not always act in their member capacity. In case someone is a member of more than one organization, this means that she might at some point act in her capacity of member of one organization but not the other(s). The fact that a particular collection of individuals 
may constitute two organizations at the same time does not entail that all the actions they perform during a particular period constitute actions of these organizations.

Can the Enactment Account of Constitution also solve the puzzle concerning institutions without members? The basic idea that constitution views try to capture is that some objects are in some sense made up of other objects. If it is possible for organizations to exist without having any members, however, it seems we have to countenance the possibility that some objects are made out of thin air: apparently, there can be constituted objects without constituters. One might, in response, be inclined to say that we should conceive of organizations as immaterial objects. Baker (2000) regards it as conceivable that immaterial objects are constituted by other objects. However, she adds the eminently plausible condition that, if a constituted object is immaterial, its constituter is immaterial as well. And we have seen that at least some organizations are constituted by people. Now it is slightly odd, to say the least, to hold that some organizations are materially constituted, while others are immaterial entities.

Personally I know of no organization that has no members. And the idea that is possible is certainly less compelling than the possibility of two organizations being constituted by the same people (see Dan-Cohen 1986 for an argument that this is possible). There are, however, other institutions that pose an analogous problem. Consider the papacy. The papacy does not cease to exist when a pope dies. The period between the death of a pope and the election of a new one is known as a papal interregnum. The papal interregnum is a case of an institution without an instantiation, or an institution without a material basis.

In spite of appearances, an account of constitution is not the place to look for a solution to this second puzzle. Instead, the Status Account of Institutions resolves it. In case of a papal interregnum, the papacy exists in the sense that its constitutive rule is still in force. There is no pope, however, because there is no particular person in the relevant context that meets the requisite conditions. The College of Cardinals will be busy arranging a papal conclave, but until a pope has been elected the seat will be vacant. If it is indeed possible for organizations to exist without having any members, a similar story can presumably be told. There will be a particular statute or constitution in which the structure of the organization is specified. And there will be people responsible for filling its positions, if not now then at some later point in time. Thus, the solution to the second puzzle is that an institution can exist without being instantiated. The Status Account of Institutions serves to make precise what this means: the institution exists due to the collective acceptance of a constitutive rule; it is not instantiated because there is no entity that meets the $X$-conditions laid down in that rule.

Location Problems do not only arise for institutions that have members. In the introduction I indicated that it also arises for electronic money. Bills and coins have a definite location. This makes it natural to think that electronic money does so as well. At the same time, however, it sounds odd to say that the money is located in a computer. If it were located there, some of us might be tempted to open it and take the money elsewhere. The thing to realize is that electronic money is not an object. Instead, electronic money is a property, a property of an individual or organization. Money is purchasing power. Whereas such power can be mediated through objects, it need not be. Electronic money is not constituted by a physical object. Hence, it has no physical location. 
The claim that electronic money is a property of a person is in fact rather plausible. Suppose that the computers that register the amount of money in your bank account are lost in a fire. Does that mean that your money has been burned to ashes? No. It might even be that if you have some record of it, the registration of the amount of electronic money you have can be restored. The reason for this is that your money is ultimately a matter of you having certain normative powers. This fact is somewhat obscured by money that is physically realized by coins and bills (see my 2011a for more on this). ${ }^{22}$ The upshot is that the Status Account of Institutions in combination with the Enactment Account of Constitution can solve not only the Location Problem for organizations, but also a range of other Location Problems of institutional entities.

The overarching Location Problem in social ontology consists of the fact that we sometimes have conflicting intuitions about the location of social entities. We are inclined to think that electronic money must have a physical location just as bills and coins do. However, no plausible candidate can be identified as the object that constitutes electronic money, which creates a puzzle as to how it can exist at all. Institutions without members, such as the papacy during a papal interregnum, pose a problem because it is hard to conceive of how such an institution can exist if it has no material basis. Organizations are problematic because they can be where their members are not. I have presented solutions for these cases and venture that these solutions contain the ingredients for a recipe that can be used for solving related location problems in social ontology.

A background presupposition of the recipe is that the Enactment Account of Constitution and the Status Account of Institutions are correct. The recipe itself consists of three steps. The first thing to do is to identify the $Y$-favorable conditions that have to be satisfied in order for something to have the relevant status. These consist in part of the $X$-conditions, the conditions that an entity has to meet in order to constitute a particular status. More often than not, these conditions will make it obvious on what kind of entity the status is imposed. When this remains obscure, it may be that no suitable entity can be identified on which a particular status is imposed. In that case, the thing to do is to check whether (a property of) one or more persons can be identified as the entity (or property) that constitutes the status. If this is unsuccessful, the remaining step to be taken is to check whether a constitutive rule is in place the $X$-conditions of which are not satisfied. In that case the institution exists without being instantiated. These three guidelines form my recipe for solving Location Problems in social ontology.

\section{Ontological and methodological implications}

At the heart of my solution to the Location Problem lies the Enactment Account of Constitution. It solves the problem in a plausible and intuitive way. In this section I shall discuss the implications it has for ontology and methodology. Thus far I have characterized the position defended here as a form of materialism. In Sect. 4.1 I shall argue that it is also a form of ontological individualism. An initially attractive definition

\footnotetext{
22 As the account presented in Sect. 2.3 concerns objects, this solution requires an account of property constitution. Baker (2009) account of property constitution provides a suitable point of departure for developing the details of such an account.
} 
of ontological individualism is in terms of the thesis that social objects and properties are determined only by individuals and their properties (Currie 1984, 1988; Sawyer 2002; Pettit 2003). I shall argue that this definition has to be revised in light of the fact that physical objects and properties can play an important role in the constitution of social objects and properties.

Given the Enactment Account of Constitution, however, social objects and properties cannot be reduced to individual objects and properties not even in combination with physical objects and properties. Using a term introduced by Keith Sawyer (2002), the individualism implied by the Enactment Account is a form of "non-reductive individualism'. The irreducibility of social objects and properties has consequences for the explanation of social facts or events. According to methodological individualism, all social facts or events can be (or are best) explained in terms of facts or events concerning individuals (and physical objects) and their properties (Watkins 1952; Sawyer 2002, 2003; Zahle 2003). The irreducibility of social objects and properties, I shall argue in Sect. 4.2, implies that some social facts or events can adequately be explained in terms of other social facts or events.

The falsity of methodological individualism raises the question what role individuals play in explanations of social facts or events. I shall argue that, even when individuals play a significant role in the explanation of a social fact or event, this will often be due to the satisfaction of certain contextual conditions in virtue of which those individuals have some institutional status. And this implies that the explanation is irreducibly social after all.

\subsection{Ontological individualism}

The central claim that contemporary ontological individualists make is, roughly, that two worlds that are indiscernible with respect to individual properties must have the same social properties (Currie 1984, 1988; Sawyer 2002; Pettit 2003). This is what it means to say that the latter are determined by the former. For many purposes it is important to be precise about the details of such a supervenience claim including, in particular, its modal force. I leave these issues open here, because the claim that I defend does not depend on how they are decided. Instead, the claim concerns the supervenience base of social properties. I shall argue that it is not always plausible to construe all of the properties of objects that constitute institutional objects as individual properties. In terms of the Status Account of Institutions: it need not be the case that all $Y$-favorable conditions are properties of individuals. ${ }^{23}$

As discussed in Sect. 1, the creation of an LLC requires drafting a certificate of organization that states the geographical and mailing addresses of the initial designated

\footnotetext{
23 The supervenience base of social properties is intricate even if it is restricted to individual properties. Currie (1984) argues that social properties supervene on individual properties globally. Global supervenience serves to do justice to the fact that membership in organizations is subject to change. It also accommodates the fact that many organizations owe their existence in part to individuals who are not their members (e.g. the Secretary of State in case of LLCs; see also Epstein 2008). Currie (1984) also argues that the supervenience base of social properties should have a historical dimension (using my guiding example, an individual must have signed an operating agreement in order to be a member of an LLC).
} 
office and the street and mailing addresses of the company's initial agent for service of process. Arguably, addresses are institutional phenomena themselves. However, they supervene on physical properties. And the physical properties at issue are not plausibly construed as properties of individuals. Consider electronic money as another example, and suppose once again that the computers of your bank are lost in a fire. Even though your money has not been burned to ashes, your ability to exercise your purchasing power may have been severely compromised. However, data stored on a computer are not individual properties on any sensible conception of what individuals and their properties are. Just as the previous example, this one concerns $Y$-favorable conditions. Both examples reveal that $Y$-favorable conditions can extend beyond individual properties and include physical properties.

Brian Epstein $(2008,2009)$ has put forward a similar argument concerning the supervenience base of social properties. However, he concludes from it that ontological individualism is false. The argument from which he starts is that social properties are often determined by physical properties that are 'not plausibly individualistic' because they are 'not in anyone's local vicinity, and that no one has ever encountered' (Epstein 2009, p. 190). One of his examples is eligibility for Federal hurricane assistance. He points out that whether an event is a hurricane depends on 'factors beyond those with which any individual has a causal connection with' (ibid., p. 206). Surely factors no individual has a causal connection with are not properties of individuals. Epstein maintains that this argument entails ontological holism. He relies on a definition of ontological individualism such as the one from which I started above: social objects and properties are determined (only) by individuals and their properties. This thesis is indeed refuted by the arguments he and I have presented. Rather than concluding that ontological holism must be true, however, I suggest that the definition of ontological individualism be revised in the following way: social objects and properties are determined (only) by individual and physical objects and properties.

Epstein discusses how J.W.N. Watkins $(1955,1959)$ treats physical objects and properties in the various definitions of individualism he has provided. At some point Watkins argues that they bear on social matters only 'by affecting people, or through people's ideas about them' (1955, p. 58). Earlier Watkins had already maintained that social phenomena are to be reduced to psychological phenomena (1952, pp. 28-29). In light of this it is important to reject what Epstein calls 'psychologism with regard to social properties' (2009, p. 202). This means that not all social facts or events can be explained in terms of individuals and their attitudes. Accepting this claim, however, does not require abandoning ontological individualism. As Epstein (2009, p. 202) notes, Watkins (1959, p. 320) explicitly accommodated physical factors in a more recent definition of individualism. It is hard to see what physical factors have to do with holism. In light of this, I regard accepting the suggested revised definition of ontological individualism as more attractive than embracing ontological holism.

\subsection{Methodological holism}

What are the methodological implications of non-reductive individualism? Given that it is a form of ontological individualism, one might expect it to entail methodological 
individualism. This is the thesis that all social facts or events can be (or are best) explained in terms of facts or events concerning individuals (and physical objects) and their properties (Watkins 1952; Sawyer 2002, 2003; Zahle 2003). If this thesis is true, any social fact or event can in principle be explained without invoking social objects or properties. Note, however, that the individualism I endorse is non-reductive. As I shall discuss shortly, non-reductive individualism entails methodological holism. This is the thesis that at least some social facts or events can be or are best explained in terms of other social facts or events. ${ }^{24}$

In the past two decades, a number of self-described ontological individualists have argued that their position is consistent with methodological holism. ${ }^{25}$ At the heart of their argument lies the observation that the individualist supervenience thesis is consistent with the claim that social properties cannot be reduced to individual properties. They maintain that social properties can in fact not be reduced to individual properties because social properties are multiply realizable. ${ }^{26}$ Subsequently, they argue from the irreducibility of the social to the conclusion that there are social laws, causes, or mechanisms that cannot be reduced to individual laws, causes, or mechanisms. Hence, at least some explanations of social facts or events are irreducibly social. ${ }^{27}$

My argument for methodological holism differs from this line of argument in that it does not invoke multiple realizability. I grant that many institutional entities and properties are multiply realizable. In fact, one of the virtues of the account of institutions that I defend is that it accommodates multiple realizability in a natural way: $Y$-favorable conditions can (and often do) differ across contexts. ${ }^{28}$ My argument starts instead from the Location Problem in social ontology. As discussed above, the Enactment Account of Constitution solves this problem. On this account, many social objects and properties cannot be reduced to individual (and physical) objects and properties. This entails that at least some explanations of social facts or events cannot be reduced either: these explanations have to invoke social objects or properties. And this in turn is exactly what the methodological holist affirms.

\footnotetext{
${ }^{24}$ Methodological holism is the negation of methodological individualism (see Watkins 1957, p. 106, Sawyer 2002, p. 537, 2003, p. 220, Zahle 2003, p. 77). This is why I formulate individualism as a claim about all social facts or events, and holism as a claim about some of them. Note that, whereas Watkins and Sawyer define methodological individualism in terms of explanation, Zahle characterizes it in terms of theory reduction.

25 See Little (1991), Kincaid (1995), Sawyer (2002), Sawyer (2003), and Zahle (2003). These philosophers have been significantly influenced by a similar line of argument in the philosophy of mind propounded by Davidson (1970), Fodor (1974), and Putnam (1975). See Greve (forthcoming) for a criticism of Sawyer's non-reductive individualism.

${ }^{26}$ Sawyer (2002) argues that multiple realizability as such is not enough. He maintains that in order to be irreducible to individual properties, social properties must be wildly disjunctive (and he goes on to argue that they are).

27 Other ontological individualists resist methodological holism. Mellor (1982), for instance, accepts typeidentities (bridge laws) between the social and the individual. Currie $(1984,1988)$ rejects type-identity and accepts that there are irreducible social kinds. However, he does not believe there are any irreducible social causal laws.

${ }^{28}$ Even within one particular context, different kinds of entities can instantiate the same status. Money, for instance, usually comes in several kinds of coins and bills. Such context-specific multiple realizability can be accounted for by allowing for disjunctive $X$ terms.
} 
Consider the Modigliani-Miller theorem in financial economics as an example. The theorem states that the value of a firm is independent of its capital structure (Modigliani and Miller 1958). Modigliani and Miller (1963) showed that the theorem breaks down when the assumption that taxes are absent is relaxed. Many tax regimes favor bonds over shares. In such a tax regime it is optimal to finance firms with debt only (given the other idealizing assumptions that remain in place). In a tax regime that favors shares over bonds it is optimal to use shares for financing firms. This reveals that tax regimes play an important role in the explanation of the way in which firms are financed. Now, a tax regime is an institutional entity just as LLCs and electronic money are. It is an institutional entity that can be explicated in terms of the Status Account of Institutions and the Enactment Account of Constitution. A tax regime, then, is an irreducible social phenomenon (that depends on physical properties given that tax regimes differ across states). And the capital structures that tax regimes serve to explain are irreducibly social properties of firms. Therefore, explanations that employ the tax-adjusted Modigliani-Miller theorem explain a social event in terms of a social event. ${ }^{29}$

One might object that this illustration does not support methodological holism because the explanation can be reformulated in terms of individual agents and their actions. A closer look at the example, however, reveals that this cannot be done. Consider a firm that changes its capital structure by issuing new shares. The causal process can be explicated at the social level with the tax office, the firm, and its shareholders as agents. These are all social entities that involve institutional statuses. At the same time, however, particular individuals obviously play a crucial role in the process. Think, for instance, of the (authorized) members of the firm and individual shareholders. These individuals have their statuses in virtue of the satisfaction of the relevant favorable conditions. In many explanations, most of those conditions are background conditions, and the causal powers that do the explaining will then inhere in individual agents. Such explanations can appear to be individualistic, but such appearances are deceiving. The individuals are causally effective in the way they are only because the background conditions are satisfied, and those background do not consist only of individuals (and physical objects) and their properties. In cases such as this one, explanations are successful in virtue of the role played by the wider social and physical context. The Enactment Account, then, does justice to the intuition underlying methodological individualism - that the action is where the individuals are-but supports a methodologically holist position.

\section{Conclusion}

Ruben believes that groups are located wherever their members are. He also maintains that the locations of organizations and their members need not coincide. I have argued that organizations such as LLCs owe their existence to the imposition of institutional statuses on collections of individuals. Now suppose that a group of individuals is

\footnotetext{
29 All examples from scientific practice are, of course, premised on the adequacy of the scientific theory. Note, however, that even if the Modigliani-Miller theorem is false, the claim at issue here-that tax regimes influence capital structure-is independently plausible. See Hindriks (2008b, 2011b) for more on the methodology of the Modigliani-Miller theorem.
} 
transformed into an LLC. If Ruben is right, such a status imposition can in a sense lead to a change of location. At first sight this seems odd. The Status Account of Institutions that I have defended in this paper, however, enables us to understand why this claim makes sense. The legal powers imposed on the group require that an institutional location be assigned to the organization it constitutes. And that institutional location can differ from the non-institutional location of the group that constitutes the organization. The fact that organizations have an institutional location explains why we are hesitant to point to the location of their members when asked about their location. And this is how it should be.

Our intuitions about the location of an organization seem to conflict because some of them do not really pertain to the organization, but to their members. I have made the idea that the two can have different locations precise by providing an account of constitution that does not require the constituting and the constituted object to spatially coincide. The alternative requirement that I have defended is that the individual members enact the actions of the organization or authorize others to do so. The account defended here is non-reductive. Only a non-reductive conception of constitution can accommodate the conflicting intuitions we have about the location of institutional entities such as organizations. Thus, the Location Problem provides the motivation for a kind of non-reductive materialism or individualism about such entities. In addition to this, I have defended methodological holism arguing that, given their irreducibility, institutional entities can play an essential role in social explanations.

The Enactment Account of Constitution has been embedded in the Status Account of Institutions. This enabled me to make sense of what institutional locations are and why they are important. Institutional entities involve statuses that consist of normative powers. Institutional locations play an important role in determining which normative powers an institutional entity has. And normative power is what institutional reality is all about.

Acknowledgments I presented this paper at Reduction and the Special Sciences, a conference held at Tilburg University (the Netherlands), and in the Research Seminar Mind and Action at the Radboud University Nijmegen, both in April 2008. I gratefully acknowledge helpful comments from the audiences there. I also thank Lynne Rudder Baker, Arno Wouters, and three anonymous referees for their written comments.

Open Access This article is distributed under the terms of the Creative Commons Attribution Noncommercial License which permits any noncommercial use, distribution, and reproduction in any medium, provided the original author(s) and source are credited.

\section{References}

Baker, L. R. (1997). Why constitution is not identity. Journal of Philosophy, 94, 599-621.

Baker, L. R. (2000). Persons and bodies: A constitution view. Cambridge: Cambridge University Press. Baker, L. R. (2007). The metaphysics of everyday life. Cambridge: Cambridge University Press.

Baker, L. R. (2009). Non-reductive materialism. In B. P. McLaughlin, A. Beckermann, \& S. Walter (Eds.), The Oxford handbook of philosophy of mind (pp. 109-127). Oxford: Oxford University Press.

Copp, D. (1984). What collectives are: Agency, individualism and legal theory. Dialogue, 23, $249-269$.

Currie, G. (1984). Individualism and global supervenience. British Journal for the Philosophy of Science, 35, 345-358. 
Currie, G. (1988). Realism in the social sciences: Social kinds and social laws. In R. Nola (Ed.), Relativism and realism in science (pp. 205-227). Dordrecht: Kluwer.

Dan-Cohen, M. (1986). Rights, persons, and organizations: A legal theory for bureaucratic society. Berkeley: University of California Press.

Davidson, D. (1970). Mental events. In L. Foster \& J. W. Swanson (Eds.), Experience and theory (pp. 79101). Amherst: University of Massachusetts Press.

Doepke, F. (1982). Spatially coinciding objects. Ratio, 24, 45-60.

Effingham, N. (2010). The Metaphysics of Groups. Philosophical Studies, 149, 251-267.

Epstein, B. (2008). When local models fail. Philosophy of the Social Sciences, 38, 3-24.

Epstein, B. (2009). Ontological individualism reconsidered. Synthese, 166, 187-213.

Fodor, J. A. (1974). Special sciences (Or: The disunity of science as a working hypothesis). Synthese, 28, 97-115.

Gilbert, M. (1989). On social facts. London: Routledge.

Gillett, C. (2002). The dimensions of realization: A critique of the standard view. Analysis, 62, 316-323.

Goldman, A. I. (1970). A theory of human action. Prentice-Hall: Englewood Cliffs.

Greve, J. (forthcoming). Emergence in sociology: A critique of nonreductive individualism. Philosophy of the Social Sciences.

Hedstrom, P., \& Svedberg, R. (eds.). (1998). Social mechanisms: An analytical approach to social theory. Cambridge: Cambridge University Press.

Hindriks, F. (2008a). The status account of corporate agents. In H. B. Schmid, K. Schulte-Ostermann, \& N. Psarros (Eds.), Concepts of sharedness-essays on collective intentionality (pp. 119-144). Frankfurt: Ontos Verlag.

Hindriks, F. (2008b). False models as explanatory engines. Philosophy of the Social Sciences, 38, 334-360.

Hindriks, F. (2009). Constitutive rules, language, and ontology. Erkenntnis, 71(2), 253-275.

Hindriks, F. (2011a, forthcoming). But where is the university?.

Hindriks, F. (2011b, forthcoming). Explantion, understanding, and unrealistic models.

Jackson, F., \& Pettit, P. (1990). Program explanation: A general perspective. Analysis, 50, 107-117.

Kincaid, H. (1986). Explanation, Reduction and Individualism. Philosophy of Science, 53, 492-513.

Kincaid, H. (1990). Defending laws in the social sciences. Philosophy of the Social Sciences, 20(1), $56-83$.

Kincaid, H. (1995). Reduction, explanation and individualism. In M. Martin \& L. C. McIntyre (Eds.), Readings in the philosophy of the social sciences (pp. 497-515). Cambridge, MA: MIT Press.

Little, D. (1991). Varieties of social explanation. Oxford: Westview Press.

MacDonald, G., \& Pettit, P. (1981). Semantics and social science. London: Routledge and Kegan Paul.

Marchionni, C. (2008). Explanatory pluralism and complementarity: From autonomy to integration. Philosophy of the Social Sciences, 38, 314-333.

Mellor, D. H. (1982). The reduction of society. Philosophy, 57, 51-75.

Modigliani, F., \& Miller, M. (1958). The cost of capital, corporation finance and the theory of investment. American Economic Review, 48, 261-297.

Modigliani, F., \& Miller, M. (1963). Corporate income taxes and the cost of capital: A correction. American Economic Review, 53, 433-443.

Noonan, H. (1993). Constitution is identity. Mind, 102, 133-146.

Oppenheim, P., \& Putnam, H. (1958). The unity of science as a working hypothesis. Minnesota Studies in the Philosophy of Science, 2, 3-36.

Pettit, P. (2003). Groups with minds of their own. In F. F. Schmitt (Ed.), Socializing metaphysics. The nature of social reality (pp. 167-194). Lanham: Rowman \& Littlefield.

Putnam, H. (1975). Mind, language and reality. Cambridge: Cambridge University Press.

Quinton, A. (1976). Social objects. Proceedings of the Aristotelian Society, 76, 1-27.

Ruben, D. H. (1983). Social wholes and parts. Mind, 92, 219-238.

Ruben, D. H. (1985). The metaphysics of the social world. London: Routledge and Kegan Paul.

Sawyer, R. K. (2002). Nonreductive individualism part i: Supervenience and wild disjunction. Philosophy of the Social Sciences, 32, 537-559.

Sawyer, R. K. (2003). Nonreductive individualism part ii: Social causation. Philosophy of the Social Sciences, 33, 203-224.

Searle, J. R. (1969). Speech acts: An essay in the philosophy of language. Cambridge: Cambridge University Press.

Searle, J. R. (2003). Reply to Barry Smith. American Journal of Economics and Sociology, 62, 299-309. 
Searle, J. R. (1995). The construction of social reality. New York: The Free Press.

Searle, J. R. (2006). Social ontology: Some basic principles. Anthropoligical Theory, 6, 12-29.

Searle, J. R. (2010). Making the social world: The structure of human civilization. Oxford: Oxford University Press.

Smith, B. (2007). The foundations of social coordination: John Searle and Hernando de Soto. In N. Psarros \& K. Schulte-Ostermann (Eds.), Facets of sociality (pp. 3-22). Frankfurt: Ontos Verlag.

Thomson, J. J. (1998). The statue and the clay. Noûs, 32, 149-173.

Tuomela, R. (1995). The importance of Us. A philosophical study of basic social notions. Stanford: Stanford University Press.

Tuomela, R. (2002). The philosophy of social practices: A collective acceptance view. Cambridge: Cambridge University Press.

Tuomela, R., \& Balzer, W. (1999). Collective acceptance and collective social notions. Synthese, 117, $175-205$.

Uzquiano, G. (2004). The supreme court and the supreme court justices: A metaphysical puzzle. Noûs, $38,135-153$.

Wasserman, R. (2004). The constitution question. Noûs, 38, 693-710.

Watkins, J. W. N. (1952). Ideal types and historical explanation. British Journal for the Philosophy of Science, 3, 22-43.

Watkins, J. W. N. (1955). Methodological individualism: A reply. Philosophy of Science, 22, 58-62.

Watkins, J. W. N. (1957). Historical explanation in the social sciences. British Journal for the Philosophy of Science, 8, 104-117.

Watkins, J. W. N. (1959). The two theses of methodological individualism. British Journal for the Philosophy of Science, 9, 319-320.

Weber, E., \& Van Bouwel, J. (2002). Can we dispense with structural explanations of social facts? Economics and Philosophy, 18, 259-275.

Wilson, R. A. (2005). Persons, social agency, and constitution. Social Philosophy \& Policy, 22, 49-69.

Zahle, J. (2003). The individualism-holism debate on intertheoretic reduction and the argument from multiple realization. Philosophy of the Social Sciences, 33, 77-99. 